\title{
Innovations in empirical research into human trafficking: introduction to the special edition
}

\section{Ella Cockbain ${ }^{1} \cdot$ Edward R. Kleemans $^{2}$}

Published online: 25 July 2019

(C) Springer Nature B.V. 2019

When it comes to human trafficking, hype often outweighs evidence. All too often, the discourse on trafficking - increasingly absorbed under discussions of so-called 'modern slavery' too - is dominated by simplistic treatments of a complex problem, sweeping claims and dubious statistics [1-3]. Such an approach might help to win attention, investment and support for an anti-trafficking agenda in the short term, but ultimately risks causing credibility problems for the entire field and contributing to ineffective, even harmful, interventions [see, e.g., 2, 4-6]. From the 1990s onwards, levels of interest and investment in counter-trafficking expanded rapidly [3, 7, 8]. In tandem, the literature on trafficking has proliferated [9, 10]. Yet, actual empirical (data-driven) research remains relatively rare [11-14]. Of course, non-empirical approaches have value too - for example in challenging how we conceptualise trafficking or highlighting tensions in governments' or businesses' commitments to anti-trafficking measures. Nevertheless, empirical research is clearly crucial to advance understanding of the trafficking phenomenon and shape nuanced, evidence-informed policy and practice. Even where empirical research exists, its quality can be highly variable, with many publications (even peer-reviewed ones) found to fall short of even rudimentary scientific standards $[13,15]$. Additionally, there is a particular dearth of rigorous, independent evaluations of interventions [7, 13] - despite the many millions of dollars spent thus far on anti-trafficking efforts worldwide $[12,16]$.

Before proceeding, it is worth acknowledging some fundamental tensions in researching human trafficking. First, trafficking is not a neatly delineated phenomenon that can be consistently identified and readily counted $[1,2]$. Instead, it is a relatively fuzzy social construct that exists upon what is increasingly recognised as a 'continuum of exploitation' running from decent conditions through to severe abuses [17]. Second,

Ella Cockbain

e.cockbain@ucl.ac.uk

1 Department of Security and Crime Science, University College London (UCL), London, UK

2 Department of Criminal Law and Criminology, Faculty of Law, Vrije Universiteit Amsterdam, Amsterdam, The Netherlands 
trafficking is not - and has never been - 'discursively neutral terrain' [18]. Instead it is contested territory that has long been tied up with broader political, economic and ideological agendas [3, 19]. Third, trafficking is a sensitive topic involving hidden populations [20]. Whether those involved are identified at all - let alone assigned the trafficking label - is heavily contingent on other factors, ranging from victims' willingness to disclose abuses to funding and prioritisation of counter-trafficking efforts [for further discussion, see 21, 22].

Despite these issues, it would be hard to argue that the extremes of exploitation that are - or could be - conceptualised as trafficking do not merit attention and intervention. If the trafficking field is to evolve and maintain credibility, therefore, more high-quality empirical research is needed. With so many gaps, there are many directions its expansion could take. Here, we highlight some of the gaps and limitations that are particularly pronounced and well-documented. Traditionally, research has focused overwhelmingly on sex trafficking and other trafficking types have been relatively overlooked [12, 13]. Victim-focused research dominates the literature, leaving offenders comparatively neglected [23-25]. Most trafficking research is qualitative in nature and quantitative studies are far rarer, particularly those that go beyond descriptive statistics alone $[9,13]$. Accessing research data and participants is notoriously challenging and remains a key barrier to the development of the field [11, 21, 26]. On the one hand, existing datasets (e.g. police or other administrative data) have obvious under-tapped potential for academic research and could be used far more extensively and effectively $[21,27,28]$. On the other, increased investment in primary data collection - such as via survey methods - is also necessary to address questions that existing data cannot answer. Perhaps linked to difficulties accessing data, trafficking studies typically focus on a single country and robust comparative analyses across multiple jurisdictions are rare [see, e.g., 29]. Although researchers have often approached human trafficking through a criminological or sociological lens, trafficking is clearly not just a crime problem. Other disciplines, such as geography, public health, management and computer science (to name but a few), also clearly have much to contribute [see, e.g., 30-32]. Linked to this disciplinary expansion, pushback continues against exceptionalising trafficking: rather than treating it as the product of a few isolated criminals (i.e. 'bad apples'), there is a need to examine more closely how exploitation can be enabled or exacerbated by broader systems (i.e. 'bad barrels') such as those involved in the neoliberal labour market and its regulation as well as migration policies [see, e.g., 33-36]. Finally, it is not enough just to do more research on trafficking: the research itself needs to consistently meet high standards, for example in terms of methodological transparency and rigour, solid research designs and robust ethical conduct $[13,37]$.

Given this context, we are delighted this special edition begins to address many of these key gaps. The papers in it have been written by some of the world's leading academic experts on trafficking and span a range of countries, topics and approaches. What unites the contents is a shared grounding in original, empirical research and innovative contributions to the literature, be it in thematic, methodological and/or conceptual terms. Thanks to funding from the Economic and Social Research Council of the UK, the process included a symposium in London in July 2018. Lead authors came together to present their first drafts and share their feedback on one another's work; the resultant papers are all the stronger for the constructive criticism and vigorous debate that 
ensued. Overall, we are confident that this volume has much to offer for academics, policy-makers and practitioners interested in new perspectives on human trafficking. Below, we provide a short summary of each paper, followed by some brief concluding observations.

The special edition starts with a rare quantitative analysis of individual-level data on human trafficking, using data from the United Kingdom's central system for identifying trafficking victims. For a sample of 2,630 confirmed victims, Cockbain and Bowers [38] systematically compare those trafficked for sexual exploitation, domestic servitude and (other) labour exploitation. They examine similarities and differences in terms of victim demographics, the trafficking process and official responses. They find both substantial and significant differences between types, demonstrating that human trafficking is a complex and diverse phenomenon. Although different forms of trafficking are routinely conflated in research, policy and interventions, this study highlights the value of a more nuanced approach that takes into account differences between - and indeed within - trafficking types.

Qiu, Zhang and Liu [39] provide a new perspective by focusing on trafficking for forced marriage - a particularly understudied issue - in the Chinese context. Women from poor neighbouring countries, such as Myanmar, frequently look for employment opportunities in China. Due to a severe imbalance in China's sex ratio, a trafficking market has emerged to meet the demand for brides. The authors analyse 73 court cases involving 184 Myanmar women who were trafficked into China in the period 20032016. They find that most traffickers had limited education and were either unemployed or underemployed. The vast majority were Chinese nationals with good connections in both the cross-border trade and traditional matchmaking business. Most trafficking turned out to involve few formal organisational structures and occurred primarily under the guise of employment opportunities: it appeared that most victims were recruited within Myanmar in response to the offers of a job in interior China.

Wijkman and Kleemans [40] shed new light on female offenders involved in human trafficking, in particular trafficking for sexual exploitation. Analysing the court files of 150 women convicted for trafficking offences in the Netherlands, they conclude that popular conceptions of the role of women in trafficking are inaccurate and simplistic. Contrary to stereotypes of passive female victims/predatory male offenders, their analysis shows that female traffickers are neither rare nor unimportant. The roles they performed were not limited to low-ranking activities, nor were they exceptional: instead they could be similar to those of male offenders. Specific prior experiences of victimisation, such as a history of being sexually exploited, inadequately explained women's involvement in the offending. Finally, the frequent presence of male cooffenders clearly shows that offending is embedded in social relationships, including intimate (romantic) relationships.

Brunovskis and Surtees [41] offer timely insights into the complexities of identifying trafficking victims in situations of massive and rapid transit movements. Their focus is on Europe's so-called "refugee crisis" of 2015 and 2016. They draw on fieldwork in Serbia, where an extraordinarily high number of vulnerable migrants/refugees from different countries and cultural backgrounds passed through along the Balkan route over a short period of time. Opportunities to interact with these migrants/refugees in ways that would lead to victim identification and support proved heavily constrained. In such situations, the authors found it was difficult to set up appropriate and effective 
human trafficking screening mechanisms and to identify particular vulnerabilities. They conclude that the anti-trafficking framework can be difficult to apply in mass migration settings and does not always fit well with peoples' experiences. Moreover, the protections on offer may not be suitable for or wanted by those who would be eligible.

Davies and Ollus [42] situate labour exploitation - including but not limited to trafficking at the extreme end of the spectrum - firmly within the context of developments in the economy, labour markets, and society at large. Breaking with dominant approaches to anti-trafficking that tend to centre individual offenders, they focus instead on how supply chains and business practices can enable and exacerbate the exploitation of vulnerable workers. Their analysis is based on qualitative, semi-structured interviews with both workers and supply chain stakeholders (e.g. employers, intermediaries and regulators) in the UK agri-food industry $(n=27)$ and the Finnish cleaning industry $(n=38)$. They identify industry dynamics, labour subcontracting and insufficient regulatory oversight as key factors in enabling exploitation in otherwise legitimate businesses. Given the significant role of corporate practices in facilitating exploitation, the authors argue in favour of framing labour exploitation as a form of corporate crime.

Van Meeteren and Wiering [43] take a fairly unusual approach in examining labour trafficking in the context of regular rather than irregular migration, specifically a labour migration scheme for the Chinese catering industry in the Netherlands. Through an in-depth qualitative analysis of investigative files from eight such cases identified as constituting labour trafficking, the authors explore various mechanisms through which exploitation is facilitated and sustained. They focus in particular on the impact of restrictions connected to regular migrant workers' immigration status. The authors conclude that while employers and victims alike can manoeuvre within the space provided by immigration policies, these policies clearly shape relationships and dependencies in the labour market. They find, for example, that migrants' reliance on their employers for work and residence permits makes them hesitant to disobey, run away and risk the large sums they have already invested in their migration ambitions. Tied residence and work permits emerge in this way as a particularly important contributor to vulnerability to labour exploitation.

De Vries, Nickerson, Farrell, Wittmer-Wolfe, and Bouché [44] extend research on the relationship between anti-immigration sentiment and criminal justice problems and solutions, by focusing on public support for anti-trafficking efforts in the United States. Using public opinion data from a nationally representative survey with 2,000 respondents, the authors find that anti-immigration sentiment is related to greater recognition that immigrants are vulnerable to human trafficking victimisation. While antiimmigration sentiment does not impact views on general governmental prioritization of counter-trafficking policies, it is associated with less public support for services for immigrant trafficking victims. These findings might explain why, according to the authors, public policies safeguarding migrant trafficked persons have been among the most difficult to pass in the United States, despite strong overall support for government prioritisation of anti-trafficking efforts.

Overall, this special edition covered a wide range of topics, geographies, datasets and methods. Despite the variety in the approaches, some common themes can be identified, which have important implications for research, policy and practice. First, 
many contributions underscore the complexity and diversity of both trafficking and counter-trafficking activity, including in terms of attributes and attitudes of victims, offenders and the general publics. Moving away from one-size-fits-all approaches is vital to become more effective at explaining and tackling this issue. Second, many papers highlight the importance of contextual factors in understanding how trafficking and exploitation are produced, sustained and exacerbated. Greater recognition of contextual factors - both at the individual- and systems-level - is crucial in supporting more nuanced responses and identifying a wider range of avenues for intervention. Third, the articles often challenge stereotypes, debunk myths and/or question assumptions about how trafficking and counter-trafficking function. With trafficking such a 'hot' topic, it is vital that rigorous empirical research continues to provide a measured and informed counter-balance to media and political treatments that are all too often simplistic and sensationalised.

Acknowledgements We are very grateful to the Economic and Social Research Council of the UK for funding the symposium in London via Dr. Ella Cockbain's Future Research Leaders Fellowship (grant reference: ES/K008463/1). We thank the Department of Security and Crime Science at University College London for hosting the event and all who attended for their valuable contributions and feedback on others' work. We thank all the anonymous reviewers for their generosity with their time and insightful comments. Our final thanks goes to the journal's general editors, Professors Mary Dodge and Wim Huisman, for their support for this special edition and assistance throughout.

\section{References}

1. Quirk, J. (2011). The anti-slavery project: from the slave trade to human trafficking. Philadelphia: University of Pennsylvania Press.

2. O'Connell Davidson, J. (2015). Modern slavery: the margins of freedom. Basingstoke: Palgrave Macmillan.

3. Weitzer, R. (2015). Human trafficking and contemporary slavery. Annual Review of Sociology, 41, $223-242$.

4. Smith, M., \& Mac, J. (2018). Revolting prostitutes: The fight for sex workers' rights. London: Verso.

5. Zhang, S. X. (2012). Measuring labor trafficking: a research note. Crime, Law and Social Change, 58(4), 469-482.

6. Fedina, L. (2015). Use and misuse of research in books on sex trafficking: implications for interdisciplinary researchers, practitioners, and advocates. Trauma, Violence \& Abuse, 16(2), 188-198.

7. Van Der Laan, P., et al. (2011). Cross-border trafficking in human beings: prevention and intervention strategies for reducing sexual exploitation: a systematic review. Campbell Systematic Reviews(9). Available at: https://campbellcollaboration.org/media/k2/attachments/Van_der_Laan_Trafficking_ Review.pdf. Accessed 22/7/19

8. Goodey, J. (2008). Human trafficking sketchy data and policy responses. Criminology and Criminal Justice, 8(4), 421-442.

9. Laczko, F., \& Gozdziak, E. (2005). Data and research on human trafficking: A global survey. Geneva: International Organization for Migration.

10. Sweileh, W. M. (2018). Research trends on human trafficking: a bibliometric analysis using Scopus database. Globalization and Health, 14(1), 106.

11. Zhang, S. X. (2009). Beyond the 'Natasha'story-a review and critique of current research on sex trafficking. Global Crime, 10(3), 178-195.

12. Gozdziak, E., \& Bump, M. (2008). In Georgetown University (Ed.), Data and research on human trafficking: Bibliography of research-based literature. Washington, D.C.

13. Cockbain, E., Bowers, K., \& Dimitrova, G. (2018). Human trafficking for labour exploitation: the results of a two-phase systematic review mapping the European evidence base and synthesising key scientific research evidence. Journal of Experimental Criminology, 14(3), 319-360. 
14. Kleemans, E. R., \& Smit, M. (2014). Human smuggling, human trafficking, and exploitation in the sex industry. In L. Paoli (Ed.), The oxford handbook of organized crime (pp. 381-401). Oxford: Oxford University Press.

15. Kelly, L. (2005). "You can find anything you want": a critical reflection on research on trafficking in persons within and into Europe. International Migration, 43(1-2), 235-265.

16. Hoff, S. (2014). Where is the funding for anti-trafficking work? A look at donor funds, policies and practices in Europe. Anti-Trafficking Review(3), 109-132.

17. Skrivankova, K. (2010). Between decent work and forced labour: Examining the continuum of exploitation. York: Joseph Rowntree Foundation.

18. Doezema, J. (2013). Sex slaves and discourse masters: The construction of trafficking. London: Zed Books Ltd.

19. Weitzer, R. (2007). The social construction of sex trafficking: Ideology and institutionalization of a moral crusade. Politics and Society, 35(3), 447-475.

20. Tyldum, G., \& Brunovskis, A. (2005). Describing the unobserved: Methodological challenges in empirical studies on human trafficking. International Migration, 43(1-2), 17-34.

21. Cockbain, E., Bowers, K., \& Vernon, L. (2019). Using law enforcement data in trafficking research. In J. Winterdyk \& J. Jones (Eds.), The Palgrave international handbook of human trafficking (pp. 1-25). Macmillan: Basingstoke: Palgrave.

22. Cockbain, E., \& Olver, K. (2019). Child trafficking: Characteristics, complexities and challenges. In I. Bryce, W. Petherick, \& Y. Robinson (Eds.), Child abuse and neglect: Forensic issues in evidence, impact and management (pp. 95-116). New York: Elsevier.

23. Broad, R. (2015). 'A vile and violent thing': female traffickers and the criminal justice response. British Journal of Criminology, 55(6), 1058-1075.

24. Cockbain, E. (2018). Offender and victim networks in human trafficking. Abingdon: Routledge.

25. Kleemans, E. R. (2011). Expanding the domain of human trafficking research: introduction to the special issue on human trafficking. Trends in Organized Crime, 14(2-3), 95-99.

26. Tyldum, G. (2010). Limitations in research on human trafficking. International Migration, 48(5), 1-13.

27. Bjelland, H. F., \& Dahl, J. Y. (2017). Exploring criminal investigation practices: the benefits of analysing police-generated investigation data. European Journal of Policing Studies, 5(2), 5-23.

28. Laczko, F., \& Gramegna, M. A. (2003). Developing better indicators of human trafficking. The Brown Journal of World Affairs, 10(1), 179-194.

29. Jokinen, A., Ollus, N., \& Joutsen, M. (2013). Exploitation of migrant workers in Finland, Sweden, Estonia and Lithuania: Uncovering the links between recruitment, irregular employment practices and labour trafficking. Helsinki: HEUNI.

30. Oram, S., Stöckl, H., Busza, J., Howard, L. M., \& Zimmerman, C. (2012). Prevalence and risk of violence and the physical, mental, and sexual health problems associated with human trafficking: systematic review. PLoS Medicine, 9(5), e1001224.

31. Smith, D. P. (2018). Population geography I: human trafficking. Progress in Human Geography, 42(2), 297-308.

32. Crane, A., LeBaron, G., Phung, K., Behbahani, L., \& Allain, J. (2018). Innovations in the business models of modern slavery: The dark side of business model innovation. In Academy of management proceedings. Briarcliff Manor: Academy of Management 10510.

33. Gadd, D., \& Broad, R. (2018). Troubling recognitions in British responses to modern slavery. The British Journal of Criminology, 58(6), 1440-1461.

34. Scott, S. (2017). Labour exploitation and work-based harm. Bristol: Policy Press.

35. LeBaron, G. (2013). Subcontracting is not illegal, but is it unethical: Business ethics, forced labor, and economic success. The Brown Journal of World Affairs, 20, 237.

36. Lewis, H., et al. (2014). Precarious lives: Forced labour, exploitation and asylum. Bristol: Policy Press.

37. Siegel, D., \& de Wildt, R. (Eds.). (2015). Ethical concerns in research on human trafficking (Vol. 13). London: Springer.

38. Cockbain, E., \& Bowers, K. (2019. Current issue). Human trafficking for sex, labour and domestic servitude: how do key trafficking types compare and what are their predictors? Crime, Law and Social Change. https://doi.org/10.1007/s10611-019-09842-9.

39. Qiu, G., Zhang, S. X., \& Liu, W. (2019. Current issue). Trafficking of Myanmar women for forced marriage in China. Crime, Law and Social Change. https://doi.org/10.1007/s10611-019-09826-9.

40. Wijkman, M., \& Kleemans, E. (2019. Current issue). Female offenders of human trafficking and sexual exploitation. Crime, Law and Social Change. https://doi.org/10.1007/s10611-019-09840-x. 
41. Brunovskis, A., \& Surtees, R. (2019. Current issue). Identifying trafficked migrants and refugees along the Balkan route. Exploring the boundaries of exploitation, vulnerability and risk. Crime, Law and Social Change. https://doi.org/10.1007/s10611-019-09842-9.

42. Davies, J., \& Ollus, N. (2019. Current issue). Labour exploitation as corporate crime and harm: outsourcing responsibility in food production and cleaning services supply chains. Crime, Law and Social Change. https://doi.org/10.1007/s10611-019-09842-9.

43. van Meeteren, M., \& Wiering, E. (2019). Labour trafficking in Chinese restaurants in the Netherlands and the role of Dutch immigration policies. A qualitative analysis of investigative case files. Crime, Law and Social Change Current issue.

44. de Vries, I., Nickerson, C., Farrell, A., Wittmer-Wolfe, D. E., \& Bouché, V. (2019. Current issue). Antiimmigration sentiment and public opinion on human trafficking. Crime, Law and Social Change. https://doi.org/10.1007/s10611-019-09838-5.

Publisher's note Springer Nature remains neutral with regard to jurisdictional claims in published maps and institutional affiliations. 